\title{
Econometric Modelling of World Oil Supplies: Terminal Price and the Time to Depletion
}

\author{
Kamiar Mohaddes
}

1 March 2012

CWPE 1212 


\title{
Econometric Modelling of World Oil Supplies: Terminal Price and the Time to Depletion*
}

\author{
Kamiar Mohaddes \\ Faculty of Economics and Girton College \\ University of Cambridge, UK
}

March 1, 2012

\begin{abstract}
This paper develops a novel approach by which to identify the price of oil at the time of depletion; the so-called "terminal price" of oil. It is shown that while the terminal price is independent of both GDP growth and the price elasticity of energy demand, it is dependent on the world real interest rate and the total life-time stock of oil resources, as well as on the marginal extraction and scarcity cost parameters. The theoretical predictions of this model are evaluated using data on the cost of extraction, cumulative production, and proven reserves. The predicted terminal prices seem sensible for a range of parameters and variables, as illustrated by the sensitivity analysis. Using the terminal price of oil, we calculate the time to depletion, and determine the extraction and price profiles over the life-time of the resource. The extraction profiles generated seem to be in line with the actual production and the predicted prices are generally in line with those currently observed.
\end{abstract}

JEL Classifications: C23, Q31, Q47.

Keywords: Oil prices and extraction, terminal price of oil, time to depletion, nonrenewable resources, oil demand estimations, and oil extraction costs.

\footnotetext{
${ }^{*}$ We are grateful to Hashem Pesaran, Sean Holly, Massoud Karshenas, Evaleila Pesaran, Mehdi Raissi, Sergejs Saksonovs, and Melvyn Weeks as well as participants in the University of Cambridge Macro Workshop for constructive comments and suggestions. Email address: km418@cam.ac.uk
} 


\section{Introduction}

There are two main strands to the literature on exhaustible resources, and on the modelling of oil prices and supplies in particular. In one of these strands, a number of models seek to explain particular developments in oil prices mainly relying on tools from the industrial organisation literature to do so. In the other, the focus has been on the application of the Hotelling model to the oil market. While the former strand aims to model the price and extraction of oil over time, its models generally only explain individual events, such as the first oil shock, and not the evolution of oil prices over time (for an extensive survey of these models see Crémer and Salehi-Isfahani (1991)). On the other hand, the Hotelling model and its extensions develop theoretical models that yield predictions governing the rate of change of oil prices, but on their own they are not able to determine the level of oil prices and/or the profile of oil production in the world economy. Neither of these two modelling approaches helps in determining the optimal price of oil at the time of resource exhaustion. Rather, such terminal prices are assumed a priori, independent of the modelling strategy under consideration. In addition, most of these models from both strands typically abstract from the single most important factor determining energy demand, namely the real GDP, in their demand specifications. This is an important shortcoming in a growing world economy where real output is expected to rise over the foreseeable future.

In this paper, instead of looking at the growth rate of oil prices, see for instance Lin and Wagner (2007), or assuming what the price level will be at the time of depletion, as in Khanna (2001), we use a new approach to identify the price of oil at the time of depletion; referred to as the "terminal price" of oil, $P_{t, T_{t}}^{*}$. We show that the terminal price of oil does not depend on any of the demand function parameters. Thus the particular demand function chosen is not relevant for estimation of $P_{t, T_{t}}^{*}$. In fact it is illustrated that $P_{t, T_{t}}^{*}$ net of marginal extraction cost $(\alpha)$ is only determined by the real interest rate $(r)$ and the estimates of the total amount of the resource available $\left(T R_{t}\right)$ scaled by $\delta$, the scarcity coefficient. As such our framework allows for the possibility of new discoveries or revisions to the total amount of the resource available, which in turn will lead to an update in the estimate of the terminal price.

Furthermore, we specify a demand function for total energy and model the demand for oil as a fraction of this. Our setting allows the share of oil in total energy to decrease as other energy products increasingly take on more of the share of oil (as has been happening over the past three decades). Thus, a substitution effect of oil for other energy products is implicitly present in the model. We also include real output in our demand specification to capture the outward shifting energy demand curve.

We use annual data on extraction costs and production from 1975 to 2008 for a panel of 57 major oil producers to estimate the parameters of the cost function. Using these estimates and data on cumulative extraction and proven reserves, we estimate the terminal price of oil. The predicted terminal price seems sensible for a range of parameters and variables as illustrated by the sensitivity analysis. The terminal price and estimates of the demand function, obtained using annual data from 1965 to 2009 for a panel of the 65 largest oil consuming countries, are used to determine the price and extraction profiles, as well as the time to depletion $\left(T_{t}\right)$. The predicted prices of the model are close to the ones recently observed and the extraction profiles generated seem to be in line with the actual production: 
they are increasing over time and are in the right magnitude.

The rest of the paper is set out as follows: Section 2 gives a brief review of the relevant literature while Section 3 sets up and develops our theoretical model. Section 4 describes the data and the methodology used to estimate the cost and demand functions, and presents the estimation results which are used to determine the terminal price. In Section 5 we describe the methodology used to calculate the time to depletion as well as the predicted extraction and price profiles of our theoretical model. Finally, Section 6 offers some concluding remarks.

\section{Literature Review}

The two oil shocks in the 1970's generated a great deal of interest in the oil market. In order to understand and explain the way in which oil markets behave, a number of models were developed, mainly using tools from the industrial organisation literature. Some of these models emphasised the oil market as being non-competitive and the role of the Organisation of Petroleum Exporting Countries (OPEC) as a price maker. Others assumed OPEC to have no market power and therefore emphasised the role of perfect competition in the oil markets.

Within this literature three different types of non-competitive models can be identified: the first stressed the role of OPEC as a monolithic cartel (Pindyck (1978b) and Gilbert (1978)), the second group only considered a subset of OPEC to be a cartel (Hnyilicza and Pindyck (1976) and Eckbo (1976)), while the third group perceived there to be a dominant producer that held market power (Mabro (1975), Adelman (1985), and Erickson (1980)).

On the other hand, the competitive models can be broken down into four different categories. These focused on either property rights (Mabro (1986), Johany (1980), and Mead (1979)), supply shocks (MacAvoy (1982) and Verleger (1982)), exhaustibility and expectations (Griffin (1985) and Salehi-Isfahani (1995)), and target revenues (Bénard (1980), Crémer and Salehi-Isfahani (1980), and Teece (1982)) as reasons for the development of oil prices since the first oil shock.

However, none of these models can explain the evolution of oil prices or production in the past (or the future), although they are usually very good at explaining individual events such as the first or second oil shock. For instance, while the property rights model does a fairly good job at explaining the price increases during the first oil shock (1973/74), it does not explain the price increases in the two subsequent oil shocks (1978/79 and 1990/91). Similarly, while the target revenue model can partly explain the evolution of oil prices in certain periods, one can argue that governments do not set production of oil solely on the basis of balancing their budgets. Moreover, empirical tests of the non-competitive models show that OPEC can at best be described as a weak cartel with loose coordination amongst the member countries, see for instance Gulen (1996) and Salehi-Isfahani (1987). This result is also more recently supported by Marcel and Mitchell (2006) and Lin (2008) among others, who argue that while OPEC was a successful cartel in the first few decades after its establishment, the organization has not been successfully colluding over the past two decades. More importantly, the competitive and non-competitive models do not specify what oil prices will be when exhaustion is approached, nor do they give predictions for the actual price level.

Another branch of the literature takes a more theoretical approach by modifying and ex- 
tending the pioneering work of Hotelling (1931). ${ }^{1}$ Some of these studies introduce exploration and allow for the development of fields (Pindyck (1978a)), while others model uncertainty in the exploration production function (Devarajan and Fisher (1982)), or introduce backstop technology (Heal (1976) and Khanna (2001)). A number of papers attempt to model the cost function in particular: for instance, Slade (1982) proposes a cost function that depends on the output of the mine as well on the grade of the mineral, while Lin et al. (2009) allow for endogenous technology-induced shifts in the cost function. Although there are many articles that focus on adjusting the Hotelling model in one way or another so that it explains the price path of oil as observed, they generally focus on modelling the rate of change of oil prices rather than establishing what the actual price levels are, or what price will prevail in the period in which the last barrel of oil is extracted. In other cases, they make specific assumptions regarding what prices will be at the time of depletion as in Khanna (2001), or they fix the time to depletion, see for instance Lin (2007).

Thus, to our knowledge, there do not seem to be any papers which consider the determination of the terminal price of oil. At the same time, very few models in the literature include a world income variable in their oil demand specification, and even those that do fail to consider the total demand for energy as a determinant of the demand for oil in their modelling strategy. This is an important shortcoming in a growing world economy where real output is expected to rise over the foreseeable future. These shortcomings will be addressed in our theoretical model developed in Section 3.

\section{The Theoretical Framework}

\subsection{The General Framework}

Suppose that over the period $t-1$ to $t$, the production or extraction of the resource is given by $q_{t}$ and let $Q_{t}$ denote the cumulative extraction at the end of period $t$, so that:

$$
Q_{t}=\sum_{\tau=-\infty}^{t} q_{\tau}=Q_{0}+\sum_{\tau=0}^{t} q_{\tau}
$$

where $Q_{0}$ is the initial stock and is taken as given. Denote the amount of proven reserves outstanding at time $t$ by $R_{t}$ and the total amount of the resources available as $T R_{t}$; the subscript $t$ indicates that the estimate of the total available resource may vary over time, either due to data revisions or because of new resource discoveries. In order to do empirical analysis we take $T R_{t}$ to be known at any given point in time. Then it must be the case that at any point in time, $t$ :

$$
T R_{t} \geq R_{t}+Q_{t}
$$

\footnotetext{
${ }^{1}$ Although the first theoretical work on the economics of exhaustible resources has been attributed to Hotelling (1931) two much less complete papers had already dealt with this issue; Gray (1914), assuming constant prices for the resource but an increasing marginal extraction cost, developed a model looking at the optimisation problem of a single mine, while Fisher (1930) looking at the allocation of hard-tack by shipwrecked sailors, noted that the price of hard-tack increased with the interest rate.
} 
Using (1) and (2), and assuming that (2) is satisfied with equality, we obtain the resource constraint:

$$
\begin{aligned}
R_{t}+Q_{t} & =R_{t-1}+Q_{t-1} \\
R_{t}-R_{t-1} & =Q_{t-1}-Q_{t} \\
R_{t}-R_{t-1} & =-q_{t} .
\end{aligned}
$$

The cost of extraction at time $t, C_{t}\left(q_{t}, R_{t-1}\right)$, is assumed to be given by a convex function in $q_{t}$ as well as depending negatively on the amount of remaining proven reserves, the socalled stock effects. This type of cost specification is also considered by Livernois and Uhler (1987), Farzin (1992), and Favero et al. (1994) among others. It is mainly because of the pressure dynamics affecting petroleum extraction that costs vary negatively with the remaining reserves. According to these dynamics, the deeper the level of extraction, the lower the pressure, and so the more costly extraction becomes. This is because, for instance, either water or gas has to be injected to stimulate production. But even without the presence of pressure dynamics, it is still the case that extraction becomes more cost-intensive as the depth of the field increases.

We use a similar cost function to that of Favero et al. (1994), although whereas they assume that the cost function is quadratic in the rate of extraction and linear in the remaining reserves, we assume that cost of production is linear in the rate of extraction, and quadratic in the level of remaining reserves, or cumulative extraction:

$$
C_{t}\left(q_{t}, R_{t-1}\right)=\alpha q_{t}+\frac{1}{2} \delta\left(T R_{t-1}-R_{t-1}\right)^{2}>0, \quad \alpha>0, \quad \delta>0 .
$$

The above separable formulation allows the second term to be associated with the "scarcity cost" and the first term to be associated with the extraction cost.

We model consumers as being indifferent to various sources of energy, such as coal, natural gas, oil, and nuclear. Thus it is appropriate to first look at the demand for energy before determining the specific demand for oil. The main reason for this is that although its composition will change, demand for energy will continue to be present even beyond the terminal date of the depletion of oil and gas reserves. Much of the literature dealing with the Hotelling model and its extensions, for instance Lin (2009), does not include an output effect in modelling the energy demand. However, it is crucial to include a variable for real GDP in the demand function for energy, or the demand for its individual components, as it is the single most important variable for determining demand and thus consumption. In light of the above discussion we are dealing with the shortcomings in the literature when it comes to specifying an appropriate demand function for exhaustible resources by defining the total per capita demand for energy at time $t\left(D_{t}\right)$, when the real price of energy is $P_{E, t}$, to be given by an energy demand function which responds positively to the increasing world per capita income $\left(Y_{t}\right)$, thus allowing for an outward-shifting demand curve as world GDP increases, and negatively to the real price of energy:

$$
D_{t}=A Y_{t}^{\mu_{1}} P_{E, t}^{\mu_{2}}
$$

where $\mu_{1}$ and $\mu_{2}$ are the income and price elasticity of demand respectively. 
For empirical estimation of the demand function we use the actual values of real GDP per capita, however, when it comes to determining the time to depletion, $T_{t}$, and the price and extraction profiles we will assume that real GDP is growing at a constant rate, that is:

$$
\begin{aligned}
Y_{s} & =e^{g(s-t)} Y_{t}, \quad s>t, \\
s & =t+1, t+2, \ldots, T, T+1, \ldots,
\end{aligned}
$$

where $Y_{t}$ is the value of real GDP per capita at the time in which we forecast from and $g$ is the growth rate of real GDP.

Looking at Figure 1 it is reasonable to assume that a fraction of total energy consumption $\left(\phi_{t}\right)$ is provided by oil. However, this fraction has been changing over time with a downward trend. While oil consumption peaked in 1973 and was 48 percent of total energy consumption, it reached an all-time low of roughly 35 percent in 2009, with a mean of 41 percent between 1965 and 2009. Thus, using the total energy demand equation (5), we can write the demand for oil as:

$$
q_{t}^{d}=\phi_{t} D_{t}=\phi_{t} A Y_{t}^{\mu_{1}} P_{E, t}^{\mu_{2}},
$$

It must then be the case that when there are no remaining reserves from which to extract, $\phi_{t}=0$ and the amount of oil supplied is equal to zero. We set the real price of oil per barrel $\left(P_{t}\right)$ as a constant mark-up $(\varrho)$ on the real price of energy, namely

$$
P_{t}=\varrho P_{E, t},
$$

where $\varrho$ can also capture the taxation of oil relative to taxes on other energy sources by the consuming countries. This is justified by the assumption that the price of energy per unit of effective energy, for instance million tones of oil equivalent, must be approximately the same for all energy sources. The demand for oil can then be written as:

$$
q_{t}^{d}=A \phi_{t}^{1-\mu_{1}-\mu_{2}}\left(\phi_{t} Y_{t}\right)^{\mu_{1}}\left(\frac{\phi_{t}}{\varrho} P_{t}\right)^{\mu_{2}} .
$$

Finally, we assume that at any given time $t$ the market price adjusts such that supply is equal to demand. In other words, we ignore the year on year changes in stocks.

\subsection{The Optimisation Framework}

To simplify we assume, along with Pindyck (1978a) and Lin (2009) among others, that the oil market is perfectly competitive. This is equivalent to the case of a social planner who has the sole property right of all the oil in the world and sets the competitive price. We do not look at the oligopolistic case, given that oligopolistic competition is likely to affect short-run prices and not the long-run prices that we are concerned with in this paper. Thus we look at the social planner's problem and define $q_{t}$ as the the total amount extracted at time $t$ by all the firms.

The social planner's problem is then to choose an extraction profile so as to maximise the discounted stream of profits over the life of the field given the resource constraint defined in equation (3) conditional on the information set $\Omega_{t-1}$ formed at $t-1$. That is:

$$
\max _{\substack{q_{t}, q_{t+1}, \ldots \\ R_{t}, R_{t+1, \ldots}}} E\left\{\sum_{h=0}^{T_{t}} \beta^{h}\left[\pi_{t+h}\left(q_{t+h}, R_{t+h-1}\right)+\lambda_{t+h}\left(R_{t+h}-R_{t+h-1}+q_{t+h}\right)\right] \mid \Omega_{t-1}\right\},
$$


where $0 \leq \beta<1$ is the discount factor $[\beta=1 /(1+r)], r>0$ is subjective rate of discount which we shall set equal to the real interest rate, $\lambda_{t+h}$ is the lagrange multiplier, and $\pi_{t+h}$ is the profit function defined by:

$$
\pi_{t+h}\left(q_{t+h}, R_{t+h-1}\right)=P_{t+h} q_{t+h}-C_{t+h}\left(q_{t+h}, R_{t+h-1}\right)
$$

Thus we are explicitly assuming $T_{t}$ is the time to depletion; the subscript $t$ indicates that the time to depletion is endogenous, and as a result may vary as we change the date from which we forecast.

The first-order conditions for the above optimisation problem are given by:

$$
\begin{aligned}
E_{t-1}\left(\frac{d \pi_{t+h}}{d q_{t+h}}\right)+E_{t-1}\left(\lambda_{t+h}\right) & =0 \\
\beta E_{t-1}\left(\frac{d \pi_{t+h+1}}{d R_{t+h}}\right)+E_{t-1}\left(\lambda_{t+h}\right)-\beta E_{t-1}\left(\lambda_{t+h+1}\right) & =0
\end{aligned}
$$

where $E_{t-1}$ denotes expectations conditional on the information set $\Omega_{t-1}$. Given our cost function (4) we have:

$$
\begin{aligned}
\frac{d \pi_{t+h}}{d q_{t+h}} & =P_{t+h}-\frac{d C_{t+h}\left(q_{t+h}, R_{t+h-1}\right)}{d q_{t+h}} \\
& =P_{t+h}-\alpha
\end{aligned}
$$

and:

$$
\begin{aligned}
\frac{d \pi_{t+h+1}}{d R_{t+h}} & =-\frac{d C_{t+h+1}\left(Q_{t+h}\right)}{d Q_{t+h}} \times \frac{d Q_{t+h}}{d R_{t+h}} \\
& =\frac{d C_{t+h+1}\left(Q_{t+h}\right)}{d Q_{t+h}}=\delta Q_{t+h} .
\end{aligned}
$$

Hence given equations (12) - (15) the first-order conditions can be written as:

$$
\begin{aligned}
E_{t-1}\left(P_{t+h}-\alpha\right)+E_{t-1}\left(\lambda_{t+h}\right) & =0, \\
\delta \beta E_{t-1}\left(Q_{t+h}\right)+E_{t-1}\left(\lambda_{t+h}\right)-\beta E_{t-1}\left(\lambda_{t+h+1}\right) & =0 .
\end{aligned}
$$

Since $\lambda_{t+h}$ is unobserved we need to eliminate it in order to derive a pricing rule. Noting that we can iterate equation (16) forward one period and write it as:

$$
-E_{t-1}\left\{E_{t} \lambda_{t+h+1}\right\}=E_{t-1}\left\{E_{t}\left(P_{t+h+1}-\alpha\right)\right\},
$$

which assuming expectations are formed consistently can in turn be written as:

$$
-E_{t-1}\left(\lambda_{t+h+1}\right)=E_{t-1}\left(P_{t+h+1}-\alpha\right) .
$$

Substituting for equation (19) in (17) and using equation (16) to eliminate $\lambda_{t+h}$ in (17):

$$
\delta \beta E_{t-1}\left(Q_{t+h}\right)-E_{t-1}\left(P_{t+h}-\alpha\right)+\beta E_{t-1}\left(P_{t+h+1}-\alpha\right)=0,
$$


which simplifies to the pricing rule:

$$
E_{t-1}\left(P_{t+h}-\alpha\right)=\beta E_{t-1}\left(P_{t+h+1}-\alpha\right)+\beta \delta E_{t-1}\left(Q_{t+h}\right), \quad h=1,2, . . .
$$

Note if $\delta=0$, then (21) is the Hotelling rule, namely price of resource net of marginal extraction cost (here $\alpha$ ) is expected to rise with the discount rate, $r$.

Suppose that at time $t$, and given the estimate of the total resource at the time, $T R_{t}$, complete depletion is expected to occur at time $t+T_{t}$, namely $T_{t}$ periods ahead of the estimation date, $t$. We refer to $T_{t}$ as the "time to depletion". Setting $h=T_{t}$ we now have

$$
E_{t-1}\left(P_{t+T_{t}}\right)=\alpha(1-\beta)+\beta E_{t-1}\left(P_{t+T_{t}+1}\right)+\beta \delta E_{t-1}\left(Q_{t+T_{t}}\right) .
$$

Since oil is expected to be depleted at time $t+T_{t}$, it must be that $E_{t-1}\left(Q_{t+T_{t}}\right)=T R_{t}$ and $E_{t-1}\left(q_{t+T_{t}+1}\right)=0$; that is in the period after which the last barrel of oil is extracted, extraction of oil must be equal to zero and the total cumulative extraction must be equal to the estimate at time $t$ of total resource available. Hence:

$$
E_{t-1}\left(P_{t+T_{t}}\right)=\alpha(1-\beta)+\beta E_{t-1}\left(P_{t+T_{t}+1}\right)+\beta \delta T R_{t} .
$$

We now need to specify the expectations of real oil prices in the period after which oil is depleted, namely we need to specify a value for $E_{t-1}\left(P_{t+T_{t}+1}\right)$. It would not be appropriate to use the demand function for oil given in (9) at $t+T_{t}+1$ to find out what prices will prevail at time $t+T_{t}+1$. The reason for this is that we have assumed that the period after the depletion of oil resources, $\phi_{t+T_{t}+1}=0$, and so there is no demand relationship between real oil prices and oil production in the period $t+T_{t}+1$; in other words, there is no oil left in this period for a transaction price to exist. Instead we need to set $E_{t-1}\left(P_{t+T_{t}+1}\right)$ to the price of non-oil energy expected in the period immediately after which oil is completely depleted. It is clear that the analysis can be carried out for any given choice of $E_{t-1}\left(P_{t+T_{t}+1}\right)$, which is in accordance with the random walk model of oil prices and is likely to produce a good approximation. But to simplify the analysis in what follows we assume that $E_{t-1}\left(P_{t+T_{t}+1}\right)=$ $E_{t-1}\left(P_{t+T_{t}}\right)$, namely the expected price of non-oil energy, in oil equivalent units, is the same as the expected terminal price of oil. In a continuous time setting this would correspond to the smooth pasting condition often used in the solution of stochastic differential equations. Under these conditions and denoting the expected terminal price of oil formed at time $t$ by $P_{t, T_{t}}^{*}=E_{t-1}\left(P_{t+T_{t}}\right)$, we have

$$
\begin{aligned}
P_{t, T_{t}}^{*} & =\beta P_{t, T_{t}}^{*}+(1-\beta) \alpha+\beta \delta T R_{t} \\
& =\alpha+\frac{\beta}{(1-\beta)} \delta T R_{t} \\
P_{t, T_{t}}^{*} & =\alpha+\left(\frac{\delta}{r}\right)\left(Q_{t}+R_{t}\right)
\end{aligned}
$$

Therefore, the terminal price of oil, $P_{t, T_{t}}^{*}$, is then uniquely defined by equation (24). Note that for the infinity horizon case, one can derive the same result as in (24) by using the pricing equation (21) and letting the time horizon go to infinity. It is interesting to note 
that the terminal price does not depend on any of the demand function parameters, thus the particular demand function chosen is not relevant for estimation of $P_{t, T_{t}}^{*}$. In fact, $P_{t, T_{t}}^{*}$ net of marginal extraction cost, $\alpha$, is only determined by the real interest rate $(r)$ and the estimates of the total amount of the resource available $\left(T R_{t}\right)$ scaled by $\delta$, the scarcity coefficient.

If exhaustion was not an issue then it must be the case that the scarcity cost parameter is equal to zero $(\delta=0)$ and thus the terminal price $(24)$ is such that price is equal to marginal extraction cost; which is indeed the pricing rule that will be followed by competitive producers.

Remember that the estimate of total resources available $\left(T R_{t}\right)$ is made up of two parts: cumulative production $\left(Q_{t}\right)$ and amount of proven reserves $\left(R_{t}\right)$, see equation (2). For any given time $Q_{t}$ cannot be revised in the sense that we always know how much has been extracted (although this is subject to measurement errors). However, this is not the case for $R_{t}$ which may be revised upwards or downwards. Thus, our framework allows for the possibility of discovering new reserves or revision to the total resource at any given time period. From equation (24) we see that if the total resource available is revised upwards the terminal price should then increase. This is an interesting property of the terminal price as it appears counter-intuitive, since we usually think of the price declining as supply increases. But note that an increase in $T R_{t}$ while implying that more of the resource is available it also means that future costs of extraction will increase as the cost function (4) is increasing in cumulative extraction with a positive $\delta$. If $\delta=0$, this effect is not present and we return to the case of a competitive producer with an inexhaustible resource.

As suspected an increase in the marginal extraction cost $(\alpha)$ implies an increase in the terminal price, as does an increase in the scarcity parameter $(\delta)$. On the other hand an increase in the subjective rate of discount $(r)$ leads to a fall in the terminal price of oil.

\section{Empirical Application}

Our aim is to estimate the terminal price of oil $\left(P_{t, T_{t}}^{*}\right)$ for different values of $t$ over the period 2000-2010. In order to do that we need to estimate the marginal extraction cost $(\alpha)$ and the scarcity cost parameter $(\delta)$, as well as have an estimate of the total resource available $\left(T R_{t}\right)$ in the world at any given time $t$. Thus we require data on annual and cumulative extraction, proven reserves, cost of extraction, as well as an estimate of the subjective rate of discount $(r)$ which we shall set equal to the real world interest rate. Moreover, in order to determine the time to depletion $\left(T_{t}\right)$ and the extraction profile of the resource over the time of depletion, not only do we need to know the terminal price, but we also need to estimate the demand function parameters as well as the share of oil in total energy demand $\left(\phi_{t}\right)$.

The data used for the estimations are described in detail in Section 4.1. The results of the estimations of the cost and demand functions are reported in Sections 4.2.1 and 4.2.2, respectively. Using the estimated cost function parameters, we determine the prevailing terminal prices for the years 2000-2010 in Section 4.3. In addition, we examine the range within which these prices are predicted to lie when the real interest rate is allowed to vary within a 0.5 percent band and also when the scarcity parameter lies within its estimated 95 percent confidence interval. In Section 5 we will use the estimated parameters of both the cost and the demand functions as well as the predicted terminal prices to determine the time 
to depletion and to examine the shape of the extraction and price profiles.

\subsection{Data}

We use annual data for the period 1965 to 2009 on oil extraction and consumption for the largest oil consuming and producing countries, see Table 1. Our dataset covers 65 oil consuming countries, which together account for 93.4 percent of the total crude oil demanded, and 57 oil producing countries, which together produce 99.2 percent of total oil in the world. These two series are obtained from the British Petroleum (2010) Statistical Review of World Energy and the OPEC (2010) Annual Statistical Bulletin. Thus our sample of countries is very comprehensive and capture the world as a whole pretty well. In addition, we have data on total proven reserves and oil prices from British Petroleum (2010) for the years 19802010 and 1965-2009 respectively. Finally, we have access to average extraction costs from World Bank (2010b) for the 57 oil producing countries in our sample from 1975 to 2008. A more detailed description of how the variables in our dataset was constructed and its sources are provided in Table 2.

All prices in the dataset are in terms of current US dollars per barrel (Brent dated), but in order to compares prices across time we use the US consumer price index (CPI) to deflate the oil prices and the extraction costs to 2009 US dollars. From now on whenever we refer to the price of oil, unless otherwise stated, it is the real price of oil per barrel. Table 3 provides summary statistics for real oil prices and average extraction costs as well as world oil consumption, extraction and proven reserves. It is clear from this table that real world average costs are significantly lower than real oil prices. As will be explained, there is also wide cross country variations in extraction, prices, and proven reserves over this period. The reserve to extraction ratio reported in Table 3, more commonly known as the reserve-production ratio in the literature, indicates that global oil supplies should run out in roughly 40 years if oil production remains at the current rate, assuming of course that there are no significant new discoveries or technological advances over this period.

Figure 2 shows the world production of oil in million barrels per day. The sharp drop in extraction between 1979 and 1984 is explained by the fact that Saudi production was falling dramatically during this period as it was restricting its own production to keep oil prices at the 1979 level. Saudi production having been at 10.6 million barrels per day (mbd) in 1980 was less than $2 \mathrm{mbd}$ in the summer of 1985. As $2 \mathrm{mbd}$ was not a sustainable extraction level for the Saudi's, and as no other members of OPEC were adhering to their quotas, it forced the Saudi's to drop their target. As can be seen, world extraction has been increasing year on year since then. Figure 2 also plots the daily world consumption of oil. As expected there is a strong co-movement between extraction and consumption.

The evolution of the real price of oil is depicted in Figure 3. Real oil prices were relatively stable following the Second World War and up until 1973, with the average price (at 2009 US prices) during this period being around $\$ 13.75$ per barrel. However, prices increased substantially in 1973/4 as the Organisation of Arab Petroleum Exporting Countries (OAPEC) excluding Iraq, decided to introduce production cutbacks as well as an embargo on the US and Netherlands (the first oil shock). Between 1975-1978 the real price stayed at the same level, but then increased substantially once again in 1978/79 due to two supply disruptions: the Iranian Revolution and the Iran-Iraq War (the second oil shock). Between 1981 and 
1985 prices fell sharply even though Saudi production was falling dramatically, see Figure 2. However, in September of 1985, Saudi production was increased from 2 mbd to $4.7 \mathrm{mbd}$ and the price dropped from $\$ 54.95$ to $\$ 28.25$ in real terms.

Iraq's invasion of Kuwait in August 1990, causing extraction in both countries to cease, and the threat to damage Saudi oil facilities caused the price to increase to around $\$ 38.94$. However, as soon as the war ended, and with it the threat of damage to Saudi oil production, prices immediately dropped to $\$ 31.51$. The price of oil was stable between 1990-2002 fluctuating between $\$ 22.90$ and $\$ 35.50$ (prices only dropped below $\$ 20$ for a brief period in 1998/99 due to Asian crisis). However, since 2002 the real oil price has increased substantially from $\$ 29.84$ to around $\$ 104$ at the end of December 2011.

To determine the terminal price we require data on cumulative extraction $\left(Q_{t}\right)$. This is obtained by summing $q_{t}$ over the years 1965 to 2009 and adding cumulative extraction before 1965 using data from British Petroleum (2010) and OPEC (2010). Thus we are implicitly setting $Q_{1965}=129$ billion barrels. As we also have data on proven reserves, $R_{t}$, we are able to calculate the resource available, $T R_{t}$, using equation (2); that is, the total amount of the resource at time $t, T R_{t}$, is the sum of the cumulative production $Q_{t}$ and the amount of proven reserves $R_{t}$. Figure 4 shows the estimate of the total resource available as well as the estimates for proven reserves from 1980, as this is the first year in which data on proven reserves were collected. As can be seen in 1988, 1990 and 2003 there was an upward revision in proven reserves of roughly 27, 18 and 10 percents respectively. It is important to note that there have also been episodes in which proven reserves have been revised down slightly (1984/85 and 1991/92). As explained in Section 3, our theoretical framework allows for these revisions.

Note that proven reserves at any given point in time are defined as "quantities of oil that geological and engineering information indicate with reasonable certainty can be recovered in the future from known reservoirs under existing economic and operating conditions", British Petroleum (2010). Thus this measure could be unreliable. However, given that the estimates for proven reserves are consistent across a number of sources, see for instance British Petroleum (2010) and United States Department of Energy (2010), and given that at present there are no better ways of estimating the remaining oil reserves in the world, we make use of this measure.

\subsection{Empirical Results}

\subsubsection{Cost of Extraction}

For country $i$ the cost of extraction function is given by:

$$
C_{i t}=\alpha_{i} q_{i t}+\frac{1}{2} \delta\left(T R_{i t-1}-R_{i t-1}\right)^{2}+\varepsilon_{i t}
$$

Section 3.1 discussed the theoretical reasons for why the cost function should be linear in the rate of extraction and quadratic in cumulative production. However, to reduce the possibility of having trended series and to allow for heterogeneity it is better to divide (25) by $q_{i t}$. Therefore, we estimate the average cost function instead of the total cost function 
given above, that is we estimate:

$$
\begin{aligned}
\frac{C_{i t}}{q_{i t}} & =A C_{i t}=\alpha_{i}+\frac{1}{2} \delta \frac{\left(T R_{i t-1}-R_{i t-1}\right)^{2}}{q_{i t}}+u_{i t} \\
& =\alpha_{i}+\frac{1}{2} \delta \frac{\left(Q_{i t-1}\right)^{2}}{q_{i t}}+u_{i t} \\
& =\alpha+\eta_{i}+\frac{1}{2} \delta \frac{\left(Q_{i t-1}\right)^{2}}{q_{i t}}+u_{i t}
\end{aligned}
$$

where $\eta_{i}$ is the country specific residual and $\alpha$ is the mean of $\alpha_{i}$.

As previously discussed, we have priors on the sign of both cost parameters from the set-up of the model and economic theory. In order to capture the 'stocks effect' of extraction we expect $\delta>0$. In addition, the estimate of the marginal extraction cost, $\alpha$, must be positive. Given that $\alpha_{i}$ is correlated with $Q_{i t-1}$, pooled OLS and the Random Effects (RE) estimators are inconsistent for $\delta$, however, the Fixed Effects (FE) estimator is consistent. As such we report the results from pooled OLS, RE, and FE estimations, but will reply on the FE coefficients when calculating the terminal price.

Table 4 reports the results of the estimation of equation (26) using panel data between 1975 to 2008 for the 57 oil producers in our dataset. As expected, the marginal cost is positive and so is the parameter of the stocks effect. In fact the pooled OLS and RE coefficients are not that different than those of the FE ones. The results in Table 4 confirm that the marginal extraction cost being roughly $\$ 5$ is small and as such should not play a large role in determining the terminal prices (24) which must be significantly higher than $\$ 5$. Therefore, it must be the case that both the scarcity cost parameter $(\delta)$ and the real interest rate will be the main drivers of the terminal price.

\subsubsection{Demand for Oil}

Following Pesaran et al. (1998) and Pesaran et al. (1999), we employ the Pooled Mean Group (PMG) estimator to estimate the relationship between the different variables in the demand function, see equation (9). The PMG estimator is an intermediate case between the averaging and pooling methods of estimation, and involves aspects of both. It restricts the long-run coefficients to be homogenous over the cross-sections (countries), but allows for heterogeneity in intercepts, short-run coefficients (including the speed of adjustment) and error variances. The PMG estimator also generates consistent estimates of the mean of short-run coefficients across countries by taking the simple average of individual country coefficients. It can be argued that country heterogeneity is particularly relevant in short-run relationships when it comes to the demand for oil, given that countries impose subsidies and taxes on energy to different degrees. On the other hand there are often good reasons to expect that long-run relationships between variables are homogeneous across countries. Estimators that impose cross-sectional restrictions (PMG) dominate the fully heterogeneous ones (Mean Group) in terms of efficiency if the long-run restrictions are indeed valid.

We apply the methodology of Pesaran (2006) to the PMG estimator to correct for the cross-sectional dependencies that arise in the error terms from unobserved global factors, since we assume that countries are affected in different ways and to varying degrees by 
these shocks. The Cross-sectionally augmented Pooled Mean Group (CPMG) estimator is particularly appropriate for our analysis as we are interested in the long horizon estimate of the terminal prices $\left(P_{t, T_{t}}^{*}\right)$ and the time to depletion $\left(T_{t}\right)$ as well as the extraction and price profiles and as such need to estimate the long-run oil demand relationship. ${ }^{2}$

Using annual data on oil consumption, prices and real GDP per capita between 1965 and 2009 for 65 major oil producers we employ the CPMG method to estimate the following equation:

$$
\begin{aligned}
\Delta \ln \left(q_{i t}\right)= & \theta_{i} \ln \left(q_{i t-1}\right)+\mu_{i}^{\prime} \mathbf{x}_{i t}+\sum_{j=1}^{p-1} \lambda_{i j}^{*} \Delta \ln \left(q_{i t-j}\right)+\sum_{j=0}^{s-1} \gamma_{i j}^{* \prime} \Delta \mathbf{x}_{i t-j}+\xi_{i}+\varepsilon_{i t} \\
& +b_{i} \overline{\ln \left(q_{t}\right)}+c_{i} \overline{\ln \left(y_{t}\right)}+\sum_{j=0}^{p-1} l_{i j}^{*} \Delta \overline{\ln \left(q_{t-j}\right)}+\sum_{j=0}^{s-1} g_{i j}^{*} \Delta \overline{\ln \left(y_{t-j}\right)},
\end{aligned}
$$

where $\Delta \ln \left(q_{i t}\right)$ is the rate of change in the logarithm of oil consumption per capita $\left(q_{i t}\right)$ for country $i$ and year $t, \mathbf{x}_{i t}$ is a $2 \times 1$ vector of explanatory variables including the logarithm of real per capita GDP, $\ln \left(y_{i t}\right)$, and the $\log$ of the real oil prices, $\ln \left(p_{i t}\right)$. $\xi_{i}$ is the countryspecific effect and $\varepsilon_{i t}$ is the error term with a zero mean and constant variance. $\overline{\ln \left(q_{t}\right)}$, $\overline{\Delta \ln \left(q_{t}\right)}, \overline{\ln \left(y_{t}\right)}$ and $\overline{\ln \left(y_{t}\right)}$ denote the simple cross section averages of $\ln \left(q_{i t}\right), \Delta \ln \left(q_{i t}\right)$, $\ln \left(y_{i t}\right)$ and $\ln \left(y_{i t}\right)$ in year $t$. For now we will set the share of oil in energy consumption equal to its mean; in other worlds $\phi_{t}=\phi=0.41$, and thus treat as constant. In Section 5.2.1 we will look at the effects on the extraction profile as well as the time to depletion when we allow $\phi_{t}$ to be declining over time.

To eliminate cross country dependencies, arising from omitted common factors (e.g. timespecific effects or common shocks) that might influence the countries differently, the cross sectional averages of oil consumption and real GDP per capita are included in the CPMG estimator. Note also that the order of the ARDL process must be chosen to be long enough to ensure that residuals of the error-correction model are serially uncorrelated and that the regressors are weakly exogenous. Thus we allow the lag order to be chosen by the Schwarz Criterion (SBC) subject to a maximum lag of two on each of the variables, in other words $p=s \leq 2$.

Table 5 presents the cross-sectionally augmented Mean Group (CMG) and Pooled Mean Group (CPMG) estimates as well as the Hausman test statistics, distributed as chi-squared examining panel heterogeneity. ${ }^{3}$ According to the Hausman statistics, the homogeneity restriction is not rejected for individual parameters as well as jointly in all our regressions. Thus, we focus on the results obtained using the CPMG estimator, which, given its gains in consistency and efficiency over the alternative CMG estimator, is more appropriate. The results in Table 5 indicate that the error correction coefficients, $\theta_{i}$, fall within the dynamically stable range being statistically significant and negative, and therefore the null hypothesis of no long-run relation is rejected.

Our results suggest a price elasticity of demand of -0.15 , which falls in the range of the estimates obtained in the literature. For instance, Pesaran et al. (1998) find a elasticity of

\footnotetext{
${ }^{2}$ For a detailed discussion of the CPMG estimator and its advantageous over alternative panel estimation methods see Cavalcanti et al. (2012).

${ }^{3}$ The individual country results are not reported here but are available upon request.
} 
between 0.0 to -0.48 for Asian countries, Gately and Huntington (2002) report elasticities between -0.12 to -0.64 for both OECD and non-OECD countries, and Krichene (2006) obtains estimates of between -0.03 to -0.08 for various countries. Moreover, although our estimate for the income elasticity of demand (0.678) is lower than what is reported in Pesaran et al. (1998) for Asian developing countries (1.0-1.2), it is in line with the estimates of between 0.53 to 0.95 and 0.54 to 0.90 in Gately and Huntington (2002) and Krichene (2006) respectively. ${ }^{4}$

\subsection{Alternative Estimates of the Terminal Price}

The data for the total amount of the resource available, $T R_{t}$, for the years 2000 to 2010 is reported in Table 6 . While $T R_{t}$ is time dependent, depending on both cumulative extraction $\left(Q_{t}\right)$ and proven reserves $\left(R_{t}\right)$, see equation (2), it is taken as fixed at the start of any given time period for empirical application. Using $T R_{t}$, the estimate of the cost function parameters in equation (4), see Table 4 , and setting the world interest rate at 1.5 percent per annum we now calculate the terminal price using:

$$
P_{t, T_{t}}^{*}=\alpha+\left(\frac{\delta}{r}\right) T R_{t}
$$

The fourth column of Table 6 reports the benchmark case, which using the 2010 estimate of the total resource available $\left(T R_{2010}=2513\right)$, predicts a terminal price of $\$ 131.36$. The table also illustrates that using data on $T R_{t}$ between year 2000 and $2010 P_{t, T}^{*}$ varies between $\$ 104.77$ to $\$ 131.36$. This large range is due to new discoveries and technological improvements over the last decade which resulted in an upward revision of around 22 percent in proven reserves. These predictions seems sensible given that the average price of oil in 2008,2009 , and 2010 was $\$ 96.91, \$ 61.67$, and $\$ 80.39$ respectively, well below the predictions of our theoretical model for these three years. In fact the predicted terminal price of $\$ 131.36$ is very close to the projected value of $\$ 133.22$ in the Energy Information Administration (2010) International Energy Outlook for the year 2035.

Given the significant role of both the scarcity cost parameter $(\delta)$ and the interest rate in determining the terminal price it is important to evaluate how sensitive $P_{t, T}^{*}$ is to the estimates of these parameters. The analysis shows that the terminal price is highly sensitive to the level of the world real interest rate, see columns three and five of Table 6 . At the low value, one percent level, no matter the size of the total resource, $P_{t, T_{t}}^{*}$ is predicted to be large lying between $\$ 154.60$ and $\$ 194.98$. On the other hand, for a high value interest rate of two percent per annum the terminal price lies in the range of $\$ 79.85$ and $\$ 99.80$. Thus, allowing the real interest rate to vary between one and two percentage points and using the current level of estimated total resource, the terminal price of oil is predicted to lie in the range of $\$ 99.80$ and $\$ 194.98$.

We set the real interest rate at 1.5 percent, as this is the more realistic case at present, and examine the sensitivity of $P_{t, T}^{*}$ to changes in the stocks effect parameter, $\delta$. Using the 2010 estimate of the total resource, the terminal price is between $\$ 100.30$ and $\$ 162.38$ when $\delta$ lies in the 95 percent confidence interval, see columns 6-7 in Table 6. Note that when

\footnotetext{
${ }^{4}$ See also Fattouh (2007) for an extensive survey of the literature on income and price elasticities of demand.
} 
$\delta=0.00094$, the price lies in a much higher interval of $\$ 129.26$ to $\$ 162.38$ as compared to the benchmark case. Thus there is considerable uncertainty in the terminal price of oil.

In the remainder of the paper we will focus on the benchmark case in which the real world interest rate is set to the current level of 1.5 percent, $\delta$ is set to its point estimate of 0.00075 , and the total resource is set to its 2010 value of 2513 billion barrels, which yields the terminal price of $\$ 131.36$ in real terms (2009 US dollars).

\section{$5 \quad$ Extraction and Price Profiles}

Having estimated the cost function and the demand function parameters and the resulting terminal prices in Section 4, we will now turn our attention to establishing the time to depletion as well as the resulting extraction and price profiles from the start date to the time of depletion.

\subsection{Methodology}

For any given start date $t$, using the estimated demand elasticities in Table $5\left(\widehat{\mu}_{1}\right.$ and $\left.\widehat{\mu}_{2}\right)$ we calculate the amount extracted in the last period $q_{t+\widehat{T}_{t}}$ :

$$
q_{t+\widehat{T}_{t}}=A \phi_{t+\widehat{T}_{t}}^{1-\widehat{\mu}_{1}-\widehat{\mu}_{2}}\left(\phi_{t+\widehat{T}_{t}} Y_{t+\widehat{T}_{t}}\right)^{\widehat{\mu}_{1}}\left(\frac{\phi_{t+\widehat{T}_{t}}}{\varrho} P_{t, \widehat{T}_{t}}^{*}\right)^{\widehat{\mu}_{2}}
$$

where $Y_{t+\widehat{T}_{t}}$ is the real GDP in the last period and is given by:

$$
Y_{t+\widehat{T}_{t}}=e^{g\left(\widehat{T}_{t}-t\right)} Y_{t}
$$

in which $g$ is the average real GDP growth rate and $P_{t, \widehat{T}_{t}}^{*}$ is the terminal price, see Table 6, in the last period obtained using:

$$
P_{t, \widehat{T}_{t}}^{*}=\widehat{\alpha}+\left(\frac{\widehat{\delta}}{r}\right)\left(Q_{t}+R_{t}\right) .
$$

Having established the terminal price and the amount extracted in the last period, we work backwards to get price and extraction estimates of the next to the last period, $\widehat{T}_{t}-1$. We use the pricing rule derived in Section 3.2 and the resource constraint in equation (3) to obtain the estimate of prices in period $\widehat{T}_{t}-1$, namely:

$$
\begin{aligned}
P_{t+\widehat{T}_{t}-1} & =(1-\beta) \widehat{\alpha}+\beta\left(P_{t, \widehat{T}_{t}}^{*}\right)+\beta \widehat{\delta}\left(Q_{t+\widehat{T}_{t}-1}\right) \\
& =(1-\beta) \widehat{\alpha}+\beta\left(P_{t, \widehat{T}_{t}}^{*}\right)+\beta \widehat{\delta}\left(T R_{t}-q_{t+\widehat{T}_{t}}\right) .
\end{aligned}
$$

As we have estimated the marginal extraction cost, the scarcity parameter, and the terminal price in Section 4 and also have an estimate of the total amount of the resource 
available we are able to compute $P_{t+\widehat{T}_{t}-1}$. Using this value we can determine the extraction in the next to the last period, namely:

$$
\begin{aligned}
q_{t+\widehat{T}_{t}-1} & =A \phi_{t+\widehat{T}_{t}-1}^{1-\widehat{\mu}_{2}-\widehat{\mu}_{2}}\left(\phi_{t+\widehat{T}_{t}-1} Y_{t+\widehat{T}_{t}-1}\right)^{\widehat{\mu}_{1}}\left(\frac{\phi_{t+\widehat{T}_{t}-1}}{\varrho} P_{t+\widehat{T}_{t}-1}\right)^{\widehat{\mu}_{2}} \\
& =A \phi_{t+\widehat{T}_{t}-1}^{1-\widehat{\mu}_{2}-\widehat{\mu}_{2}}\left(\phi_{t+\widehat{T}_{t}-1} Y_{t} e^{g\left(\widehat{T}_{t}-t-1\right)}\right)^{\widehat{\mu}_{1}}\left(\frac{\phi_{t+\widehat{T}_{t}-1}}{\varrho} P_{t+\widehat{T}_{t}-1}\right)^{\widehat{\mu}_{2}} .
\end{aligned}
$$

Again we work backwards and determine the prices that prevail two periods before the time of depletion, that is:

$$
\begin{aligned}
P_{t+\widehat{T}_{t}-2} & =(1-\beta) \widehat{\alpha}+\beta\left(P_{t+\widehat{T}_{t}-1}\right)+\beta \widehat{\delta}\left(Q_{t+\widehat{T}_{t}-2}\right) \\
& =(1-\beta) \widehat{\alpha}+\beta\left(P_{t+\widehat{T}_{t}-1}\right)+\beta \widehat{\delta}\left(T R_{t}-q_{t+\widehat{T}_{t}}-q_{t+\widehat{T}_{t}-1}\right),
\end{aligned}
$$

and make use of $P_{t+\widehat{T}_{t}-2}$ and the demand function parameters to work out the extraction in this period:

$$
\begin{aligned}
q_{t+\widehat{T}_{t}-2} & =A \phi_{t+\widehat{T}_{t}-2}^{1-\widehat{\mu}_{1}-\widehat{\mu}_{2}}\left(\phi_{t+\widehat{T}_{t}-2} Y_{t+\widehat{T}_{t}-2}\right)^{\widehat{\mu}_{1}}\left(\frac{\phi_{t+\widehat{T}_{t}-2}}{\varrho} P_{t+\widehat{T}_{t}-2}\right)^{\widehat{\mu}_{2}} \\
& =A \phi_{t+\widehat{T}_{t}-2}^{1-\widehat{\mu}_{2}-\widehat{\mu}_{2}}\left(\phi_{t+\widehat{T}_{t}-2} Y_{t} e^{g\left(\widehat{T}_{t}-t-2\right)}\right)^{\widehat{\mu}_{1}}\left(\frac{\phi_{t+\widehat{T}_{t}-2}}{\varrho} P_{t+\widehat{T}_{t}-2}\right)^{\widehat{\mu}_{2}}
\end{aligned}
$$

We keep working backwards solving for prices in each period and then the extraction rate until the cumulative production in period $t$ reaches the same level as that of the base year $t$.

\subsection{Application}

We use the method described above and let the base year for our prediction be the end of 2010. Moreover, we set the average annual world GDP growth rate at 3.2 percent, which is equal to the benchmark growth rate used in Energy Information Administration (2010) to calculate energy demand for the years 2007-2035 (but it is also close the to the actual average growth rate of 3.8 percent for the years 1965-2009). Initially we will assume that the share of oil in energy demand remains constant, but Section 5.2.1 will investigate different cases in which the share of oil declines as it has done for the past three decades.

In 2010, the sum of proven reserves and the cumulative extraction was estimated at 2513 billion barrels. Setting the real world interest rate at the current rate of 1.5 percent the resulting terminal price is calculated to be $\$ 131.36$ per barrel, see Table $6 .^{5}$ Given $T R_{2010}=2513$ and $P_{t, T_{t}}^{*}=\$ 131.36$ we estimate the time to depletion to be in 2044 , in other words, $T_{2010}=34$.

Figure 5 depicts the extraction profile for the benchmark case, and clearly shows that with an outward shifting demand curve, production will be increasing over time until oil is depleted in 2044. In general the basic model generates extraction profiles that seem quite

\footnotetext{
${ }^{5}$ We use the point estimate of the terminal price here $(\$ 131.36)$, but the exercise in this section can be carried out for any value of the terminal price, which has an upper bound of $\$ 194.48$ in 2010 (see Table 6).
} 
sensible; firstly because they are exhibiting the same upward trend as the actual extraction profiles. This can be seen in Figure 2 which shows that the production of oil has been increasing every year since 1984. Secondly, because the predicted values are not far off from the actual ones: oil consumption is predicted to be 83.7 million barrels per day in 2011 which is very close to the actual 82.1 million barrels per day produced in 2010, see British Petroleum (2010).

Looking at the predicted price profile of the model (Figure 5) we see that the oil price in 2011 is predicted to be on average $\$ 113.83$ per barrel, which is not far off from the actual average prices of $\$ 104$ in 2011 and the current prices of around $\$ 110$ (February 2012). Just like extraction, the model predicts that prices should increase over time, reaching $\$ 131.36$ at the time of depletion. Interestingly our model suggest that the price should be $\$ 129.5$ per barrel in 2030 which is close to the predicted range of $\$ 125.69$ to $\$ 136.92$ in Lin (2009) for 2030 .

These forecasts are made with all the available information at time $t-1$, in our case end of 2010. However, the results are dependant on a number variables and parameters, with changes in each of them having implications for the terminal price and the time to depletion. Therefore, these predictions need to be updated with the arrival of new information. In particular, given the year on year increase in proven reserves and production levels, see Figures 2 and 4 , we expect $T R_{t}$ to increase overtime. This upward revision in $T R_{t}$ has two effects: (i) it increases the time to depletion for any given demand specification and output growth and (ii) it increases the terminal price. This is indeed the case for the past decade in which the predicted terminal price increased from $\$ 104.77$ in 2000 to $\$ 131.36$ in 2010 , see Table 6.

How then does our prediction regarding extraction and prices profiles compare with the work of others? Pindyck (1978a) and Pindyck (1978b) develop models that generate price profiles that increase over time and extraction profiles that increase for a large period of the life-time of the resource, while Favero et al. (1994) derive an extraction profile that is humpshaped, with initially increasing but eventually decreasing extraction rates. However, since these studies do not include real GDP in their models, we would indeed expect extraction to eventually decrease. On the other hand, Khanna (2001) illustrates how extraction increases monotonically until the resource is depleted. Thus, it seems that with real GDP included as a variable, an increasing extraction and price profile over the life-time of the resource is generally supported by the literature.

\subsubsection{Scenario Analysis: Share of Oil in Total Energy Falling}

So far we have assumed that the share of oil in total energy consumption, $\phi_{t}$, is constant. Although $\phi_{t}$ does not affect the terminal price it does have an impact on the time to depletion $\left(T_{t}\right)$ and as a result on the extraction and price profiles. Given that the share of oil has been declining for the past 36 years (Figure 1), we should allow for this to obtain more realistic extraction and price profiles. In particular, with the share of oil falling over time, we would expect that extraction and price profiles would shift downwards, in other words the growth rate of both extraction and prices should be lower.

Assuming that the share of oil declines with 0.91 percent per year, as it has done on average over the past three decades, the time to depletion is shifted forward with five years 
to 2049 as compared to the benchmark case. As expected the extraction profile is now shifted downwards, see Figure 6. The prediction of this more realistic scenario is in fact very close with those of the Energy Information Administration (2010), see Figure 7. More specifically, production in the International Energy Outlook reference case is forecasted to increase over time and reach 110.60 million barrels per day in the last year of their forecast 2035, which is almost equal to our prediction of 110.42 million.

On the other hand assuming that the share of oil will decline at double the rate of which it has been for the past 36 years, i.e. 1.82 percent per year, the extraction profile is still increasing over time but the rate of growth of extraction is now substantially smaller. As a result the time to depletion increases by 12 years, as compared to the benchmark case, and is predicted to be in 2056. Moreover, as can be seen from Figure 8, the price profile is shifted inwards resulting in lower prices for every period until depletion.

It is interesting that if the share of oil in total energy consumption is assumed to decline with 2.73 percent per year (three times the current rate), not only does time to depletion increase by 25 years (thus shifting the year of depletion to 2069) but extraction is expected to decrease for each year until oil is depleted. Moreover, the predicted prices are now exhibiting a much lower growth rate than in the other three cases, see Figure 8.

\section{Concluding Remarks}

This paper developed a theoretical framework to endogenously determine the level of oil prices at the time of depletion, the "terminal price" $\left(P_{t, T_{t}}^{*}\right)$, and provide predictions for the price level over the life-time of the resource. It was shown that the terminal price depends on the marginal extraction and scarcity cost parameters, as well as on the real interest rate and the total amount of the resource available $\left(T R_{t}\right)$, but not on the GDP growth rate or any parameters of the demand function. Our framework also allowed for the possibility of updates in the estimate of the total resource, such as new discoveries or revisions to the amount of proven reserves. An upward revision in $T R_{t}$ had two effects: (i) it increased the terminal price and (ii) it increased the duration time to depletion for any given demand elasticity and output growth rate.

Using cross-country data on extraction costs from 1975 to 2008 and on oil demand from 1965 to 2009, we estimated the parameters of our model and determined the terminal prices for the years 2000 to 2010. Our analysis showed that prices were sensitive to the real interest rate and the scarcity coefficient, as well as to the estimated total resource available. However, for almost all variations of these parameters, the terminal prices seemed sensible. Using these prices, our framework allowed us to calculate the time to depletion and outline the extraction and price paths, working backwards. In general, the basic model developed seems to generate predicted prices that are in line with the ones recently observed and sensible extraction profiles; they exhibit the same upward trend as the actual production and predict values that are not far off the current ones.

Looking at predictions made at the end of year 2010, we illustrated that in the more realistic case of a steady fall in the share of oil in total energy consumption, while terminal prices will remain unaffected, the time to depletion will be shifted forward resulting in a lower rate of oil price rises and production in each period. With the share of oil falling at 
the rate which has been witnessed over the past three decades ( 0.91 percent), the time to depletion is shifted forward by five years to 2049. Moreover, we illustrated that the predicted extraction levels under this scenario were very close to the ones forecasted by the Energy Information Administration (2010) in their reference case. However, if one assumes that the rate of decline will be at 2.73 percent per year, due to more recent serious investments in alternative energy sources, the time to depletion is shifted forward by as much as 25 years to 2069, almost double as compared to the case with a constant share. In addition, under this scenario the extraction profile is significantly altered as production will decline for every year until depletion.

The research in this paper can be extended in a number of directions. In particular, it would be interesting to apply the methodology of this paper to other exhaustible resources. For instance, data on natural gas, which has similar extraction cost properties as oil, could be used to evaluate the model.

\section{References}

Adelman, M. A. (1985). An Unstable World Market. The Energy Journal 6, 17-22.

British Petroleum, . (2010). Statistical Review of World Energy. Beacon Press.

Bénard, A. (1980). World Oil and Cold Reality. Harvard Business Review 58, 90-101.

Cavalcanti, T. V. d. V., K. Mohaddes, and M. Raissi (2012). Commodity Price Volatility and the Sources of Growth. IMF Working Paper WP/12/12.

Crémer, J. and D. Salehi-Isfahani (1980). A Theory of Competitive Pricing in the Oil Market: What Does OPEC Really Do? CARESS Working Paper 80-4, University of Pennsylvania, Philadelphia..

Crémer, J. and D. Salehi-Isfahani (1991). Models of the Oil Market. Harwood Academic Publisher.

Devarajan, S. and A. C. Fisher (1982). Exploration and Scarcity. The Journal of Political Economy 90 (6), pp. 1279-1290.

Eckbo, P. L. (1976). The Future of World Oil. Ballinger Pub Company, Cambridge, Massachusetts.

Energy Information Administration, U. S. (2010). International Energy Outlook.

Erickson, N. (1980). Developments in the World Oil Market. In R. K. Pachauri (Ed.), International Energy Studies, pp. 9-16. John Wiley \& Sons, New York.

Farzin, Y. H. (1992). The Time Path of Scarcity Rent in the Theory of Exhaustible Resources. The Economic Journal 102(413), pp. 813-830. 
Fattouh, B. (2007). The Drivers of Oil Prices: The Usefulness and Limitations of NonStructural model, the Demand-Supply Framework and Informal Approaches. Oxford Institute for Energy Studies WPM 32.

Favero, C. A., M. H. Pesaran, and S. Sharma (1994). A Duration Model of Irreversible Oil Investment: Theory and Empirical Evidence. Journal of Applied Econometrics 9, S95-S112.

Fisher, I. (1930). The Theory of Interest. Macmillan, New York.

Gately, D. and H. G. Huntington (2002). The Asymmetric Effects of Changes in Price and Income on Energy and Oil Demand. The Energy Journal 23(1), 19-56.

Gilbert, R. J. (1978). Dominant Firm Pricing Policy in a Market for an Exhaustible Resource. The Bell Journal of Economics 9(2), pp. 385-395.

Gray, L. C. (1914). Rent Under the Assumption of Exhaustibility. The Quarterly Journal of Economics 28(3), pp. 466-489.

Griffin, J. M. (1985). OPEC Behavior: A Test of Alternative Hypotheses. The American Economic Review 75(5), pp. 954-963.

Gulen, S. G. (1996). Is OPEC a Cartel? Evidence from Cointegration and Causality Tests. The Energy Journal 17, 43-57.

Heal, G. (1976). The Relationship between Price and Extraction Cost for a Resource with a Backstop Technology. The Bell Journal of Economics 7(2), pp. 371-378.

Hnyilicza, E. and R. S. Pindyck (1976). Pricing Policies for a Two-part Exhaustible Resource Cartel : The Case of OPEC. European Economic Review 8(2), 139 - 154.

Hotelling, H. (1931). The Economics of Exhaustible Resources. The Journal of Political Economy 39(2), 137-175.

International Monetary Fund, . (2012). International Financial Statistics, IMF, Washington DC.

Johany, A. D. (1980). The Myth of OPEC Cartel. John Wiley \& Sons, New York.

Khanna, N. (2001). On the Economics of Non-Renewable Resources. Binghamton University Department of Economics Working Paper 0102.

Krichene, N. (2006). World Crude Oil Markets: Monetary Policy and the Recent Oil Shock. IMF Working Paper 06/62.

Lin, C.-Y. C. (2007). Market Structure and Demand Elasticity in the World Oil Market: Insights from a Simple Hotelling Model. Working Paper, University of California, Davis.

Lin, C.-Y. C. (2008). An Empirical Dynamic Model of OPEC and Non-OPEC. University of California at Davis Working Paper. 
Lin, C.-Y. C. (2009). Insights from a Simple Hotelling Model. Natural Resources Research 18(1), 19-28.

Lin, C.-Y. C., H. Meng, T. Y. Ngai, V. Oscherov, and Y. H. Zhu (2009). Hotelling Revisited: Oil Prices and Endogenous Technological Progress. Natural Resources Research 18, 29-38.

Lin, C.-Y. C. and G. Wagner (2007). Steady-state Growth in a Hotelling Model of Resource Extraction. Journal of Environmental Economics and Management 54(1), 68 - 83.

Livernois, J. R. and R. S. Uhler (1987). Extraction Costs and the Economics of Nonrenewable Resources. The Journal of Political Economy 95(1), pp. 195-203.

Mabro, R. (1975). OPEC After the Oil Revolution. Millennium - Journal of International Studies 4, 191-199.

Mabro, R. (1986). Can OPEC Hold the Line? In R. Mabro (Ed.), OPEC and The World Oil Market: The Genesis of the 1986 Price Crisis. Oxford University Press, Oxford.

MacAvoy, P. W. (1982). Crude Oil Price As Determined by OPEC and Market Fundamentals. Ballinger Pub Company, Cambridge, Massachusetts.

Marcel, V. and J. Mitchell (2006). Oil Titans: National Oil Companies in the Middle East. Brookings Institution Press, Washington, D.C..

Mead, W. J. (1979). The Performance of Government in Energy Regulations. The American Economic Review 69(2), pp. 352-356.

OPEC, . (2010). OPEC Annual Statistical Bulletin. Ueberreuter Print und Digimedia.

Pesaran, M., R. Smith, and T. Akiyama (1998). Energy Demand in Asian Developing Economies. Oxford University Press, Oxford.

Pesaran, M. H. (2006). Estimation and Inference in Large Heterogeneous Panels with a Multifactor Error Structure. Econometrica 74 (4), 967-1012.

Pesaran, M. H., Y. Shin, and R. P. Smith (1999). Pooled Mean Group Estimation of Dynamic Heterogeneous Panels. Journal of the American Statistical Association 94(446), $621-634$.

Pindyck, R. S. (1978a). The Optimal Exploration and Production of Nonrenewable Resources. The Journal of Political Economy 86(5), 841-861.

Pindyck, R. S. (1978b). Gains to Producers from the Cartelization of Exhaustible Resources. The Review of Economics and Statistics 60(2), pp. 238-251.

Salehi-Isfahani, D. (1987). Testing OPEC Behavior: Further Results. Department of Economics, Virginia Polytechnic Institute and State University Working Paper 87-01-02.

Salehi-Isfahani, D. (1995). Models of the Oil Market Revisited. Journal of Energy Literature 1,3-21. 
Slade, M. E. (1982). Trends in Natural-resource Commodity Prices: An Analysis of the Time Domain. Journal of Environmental Economics and Management 9(2), 122 - 137.

Teece, D. (1982). OPEC Behavior: An Alternative View. In J. M. Griffin and D. Teece (Eds.), OPEC Behavior and World Oil Prices, pp. 64-93. Allen and Unwin, London.

United States Department of Energy, . (2010). Energy Information Administration.

Verleger, P. K. J. (1982). Oil Markets in Turmoil. Ballinger Pub Cambridge, Cambridge, Massachusetts.

World Bank, . (2010a). World Development Indicators, Washington DC.

World Bank, . (2010b). Adjusted Net Saving Database. 


\section{Tables and Figures}

\section{Table 1: List of the Countries in the Cost and Demand Estimations}

\begin{tabular}{|c|c|c|}
\hline Albania $^{1}$ & Germany $^{1,2,3}$ & Portugal $^{2,3}$ \\
\hline Algeria $^{1,2}$ & Greece $^{2,3}$ & Qatar $^{1,2}$ \\
\hline Angola $^{1}$ & Hong Kong ${ }^{2}$ & Romania $^{1,2}$ \\
\hline Argentina $^{1,2}$ & Hungary ${ }^{1,2,3}$ & Russian Federation $^{1,2}$ \\
\hline Australia ${ }^{1,2,3}$ & Iceland $^{2,3}$ & Saudi Arabia ${ }^{1,2}$ \\
\hline Austria $^{2,3}$ & India $^{1,2}$ & Singapore $^{2}$ \\
\hline Azerbaijan $^{1,2}$ & Indonesia $^{1,2}$ & Slovak Republic ${ }^{2,3}$ \\
\hline Bahrain $^{1}$ & $\operatorname{Iran}^{1,2}$ & South Africa ${ }^{2}$ \\
\hline Bangladesh $^{2}$ & $\operatorname{Iraq}^{1}$ & South Korea ${ }^{2,3}$ \\
\hline Belarus $^{2}$ & Italy $^{1,2,3}$ & Spain $^{2,3}$ \\
\hline Belgium $^{2,3}$ & Ireland $^{2,3}$ & Sudan $^{1}$ \\
\hline Brazil $^{1,2}$ & $\operatorname{Japan}^{2,3}$ & Sweden $^{2,3}$ \\
\hline Brunei $^{1}$ & Kazakhstan $^{1,2}$ & Switzerland $^{2,3}$ \\
\hline Bulgaria $^{2}$ & Kuwait $^{1,2}$ & Syrian Arab Republic ${ }^{1}$ \\
\hline Cameroon $^{1}$ & Libya $^{1}$ & Taiwan $^{2}$ \\
\hline Canada $^{1,2,3}$ & Lithuania $^{2}$ & Thailand $^{1,2}$ \\
\hline Chile $^{1,2,3}$ & Luxembourg $^{2,3}$ & Trinidad and Tobago ${ }^{1}$ \\
\hline China $^{1,2}$ & Malaysia $^{1,2}$ & Tunisia $^{1}$ \\
\hline Colombia $^{1,2}$ & Mexico $^{1,2,3}$ & Turkey $^{1,2,3}$ \\
\hline Congo, Republic ${ }^{1}$ & Netherlands ${ }^{1,2,3}$ & Turkmenistan $^{1,2}$ \\
\hline Czech Republic ${ }^{2,3}$ & New Zealand ${ }^{1,2,3}$ & Ukraine $^{2}$ \\
\hline Denmark $^{1,2,3}$ & Nigeria $^{1}$ & United Arab Emirates ${ }^{1,2}$ \\
\hline Ecuador $^{1,2}$ & Norway $^{1,3}$ & United Kingdom $^{1,2,3}$ \\
\hline Egypt $^{1,2}$ & Oman $^{1}$ & United States ${ }^{1,2,3}$ \\
\hline Equatorial Guinea $^{1}$ & Pakistan $^{2}$ & Uzbekistan $^{1,2}$ \\
\hline Finland $^{2,3}$ & Peru $^{1,2}$ & Venezuela $^{1,2}$ \\
\hline France $^{1,2,3}$ & Philippines $^{2}$ & Vietnam $^{1}$ \\
\hline Gabon $^{1}$ & Poland $^{2,3}$ & Yemen, Rep. ${ }^{1}$ \\
\hline
\end{tabular}

Notes: The 57 countries that are included in the cost estimations of Section 4.2 .1 are denoted by ${ }^{1}$. The 65 countries that are included in the Cross-sectionally augmented Pooled Mean Group (CPMG) analysis of Section 4.2 .2 are denoted by ${ }^{2}$. ${ }^{3}$ indicates that the country is a member of the Organisation for Economic Co-operation and Development (OECD) . 


\section{Table 2: Definitions and Sources of Variables Used in Regression Analysis}

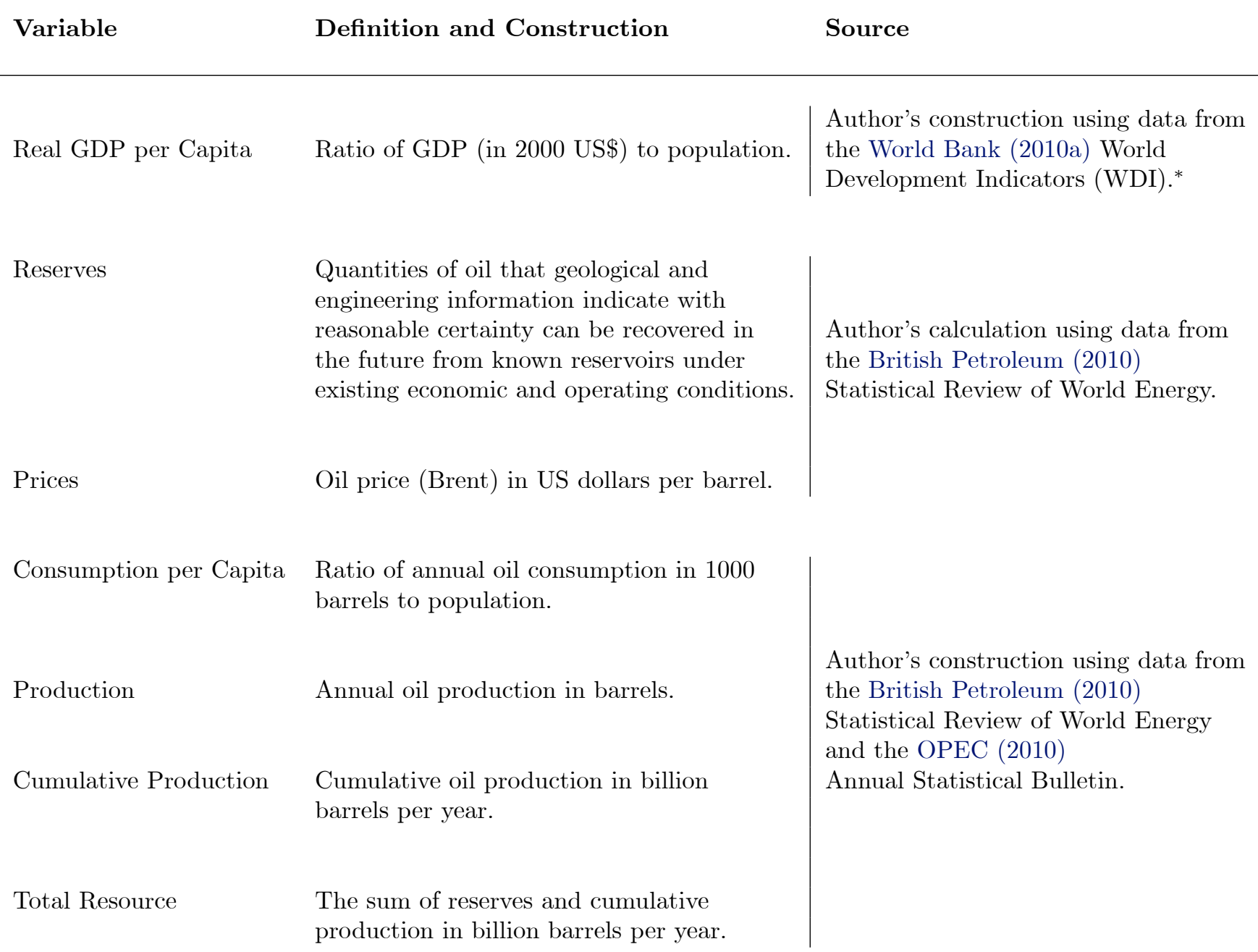

Average Cost Average cost of oil extraction in US dollars per barrel.

Consumer price index $(2000=100)$ at the end of the year.
Author's construction using data from the World Bank (2010b)

Adjusted Net Saving Database.

Author's construction using data from the International Monetary Fund (2012) International Financial Statistics.

Notes: * GDP data for Taiwan was not available from World Bank (2010a) and was instead obtained from International Monetary Fund (2012). 
Table 3: Summary Statistics on Oil Prices, Average Costs, Consumption, Extraction, and Proven Reserves

\begin{tabular}{lcccc}
\hline Variable & Mean & $\begin{array}{c}\text { Standard } \\
\text { Deviation }\end{array}$ & Minimum & Maximum \\
\hline $\begin{array}{l}\text { Real Oil Prices }\left(P_{t}\right), \\
\text { in 2009 US dollars. }\end{array}$ & 39.89 & 24.62 & 9.94 & 96.91 \\
$\begin{array}{l}\text { Real Average Costs }\left(A C_{t}\right), \\
\text { in } 2009 \text { US dollars. }\end{array}$ & 6.24 & 2.77 & 0.75 & 22.84 \\
$\begin{array}{l}\text { World Oil Extraction }\left(q_{t}\right), \\
\text { in million barrels per day. }\end{array}$ & 63.09 & 12.64 & 31.81 & 81.99 \\
$\begin{array}{l}\text { World Oil Consumption }\left(q_{t}^{d}\right), \\
\text { in million barrels per day. }\end{array}$ & 63.65 & 14.11 & 31.10 & 85.62 \\
$\begin{array}{l}\text { World Proven Reserves }\left(R_{t}\right), \\
\text { in billion barrels. }\end{array}$ & 1023.43 & 189.17 & 667.53 & 1333.13 \\
$\begin{array}{l}\text { World Proven Reserve to } \\
\text { Extraction Ratio, in years. }\end{array}$ & 40.32 & 3.72 & 29.05 & 45.68 \\
\hline
\end{tabular}

Notes: The data for proven reserves $\left(R_{t}\right)$ and world proven reserve to extraction ratio are from 1980-2009, while the data for real average cost are from 1975-2008, all other figures are based on data from 1965-2009. Author's calculations based on data from British Petroleum (2010), World Bank (2010b), and OPEC (2010). 


\section{Figure 1: Share of Oil in Total Energy Consumption (in percent), 1965-2009}

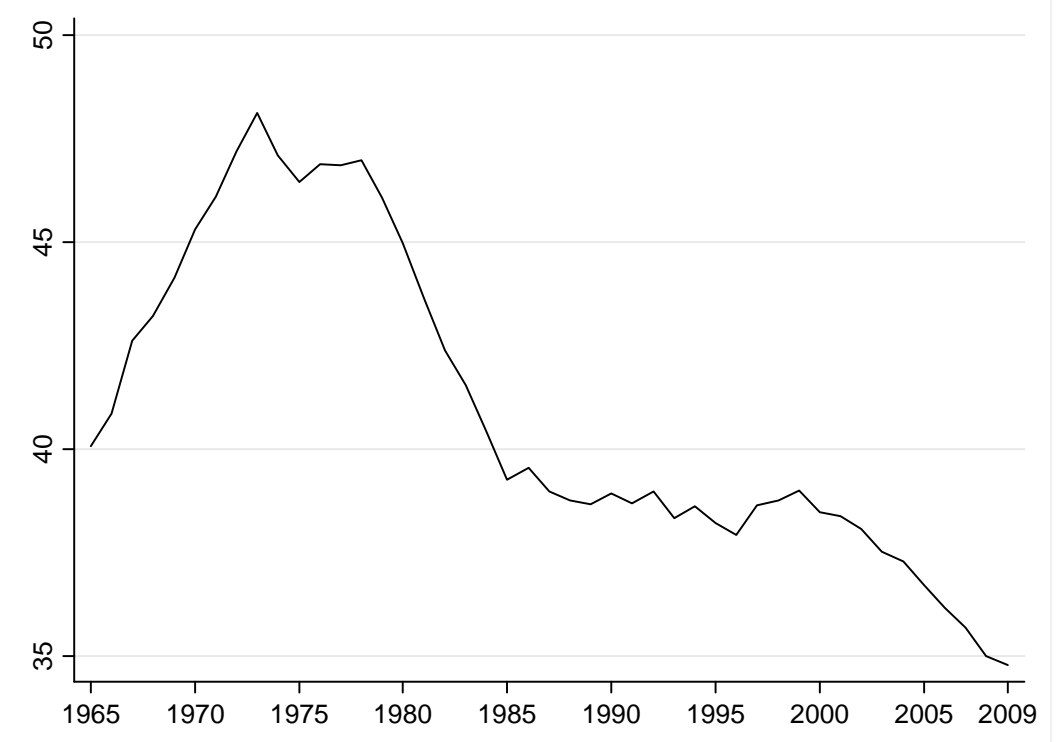

Notes: Share of Oil is the share of oil consumption in total primary energy consumption and is in percent. Author's calculations based on data from British Petroleum (2010).

Figure 2: World Oil Extraction and Consumption, 1965-2009

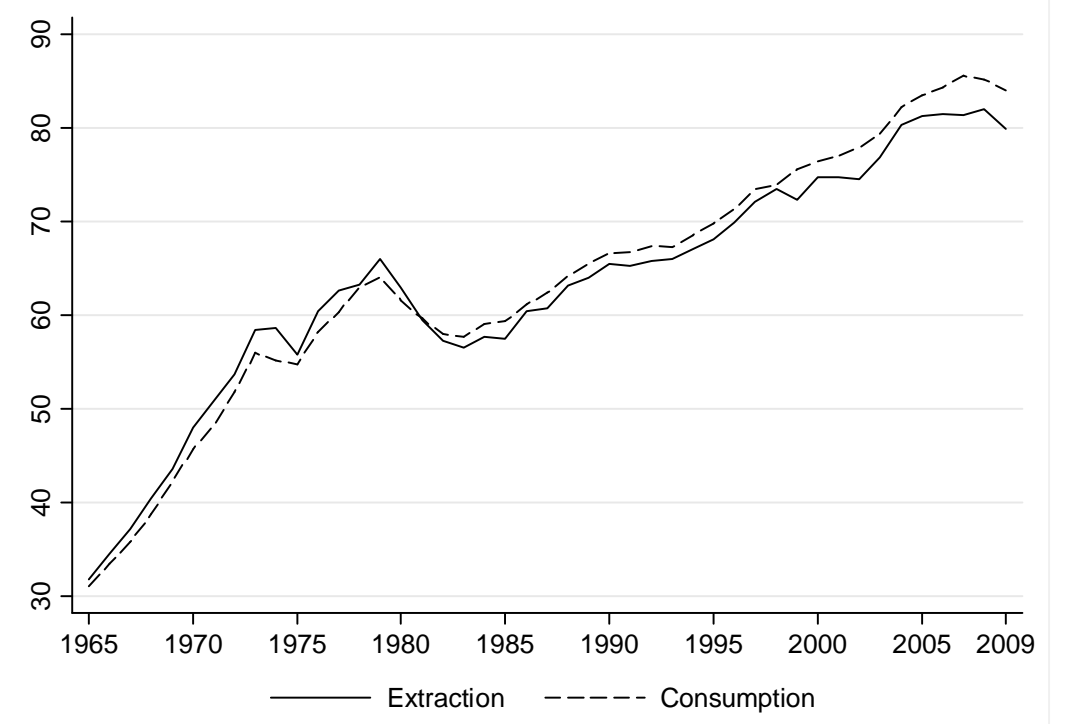

Notes: Oil Extraction and Consumption are in million barrels per day. The figure is based on data from British Petroleum (2010). 
Figure 3: Oil Prices in 2009 US Dollars, 1965-2009

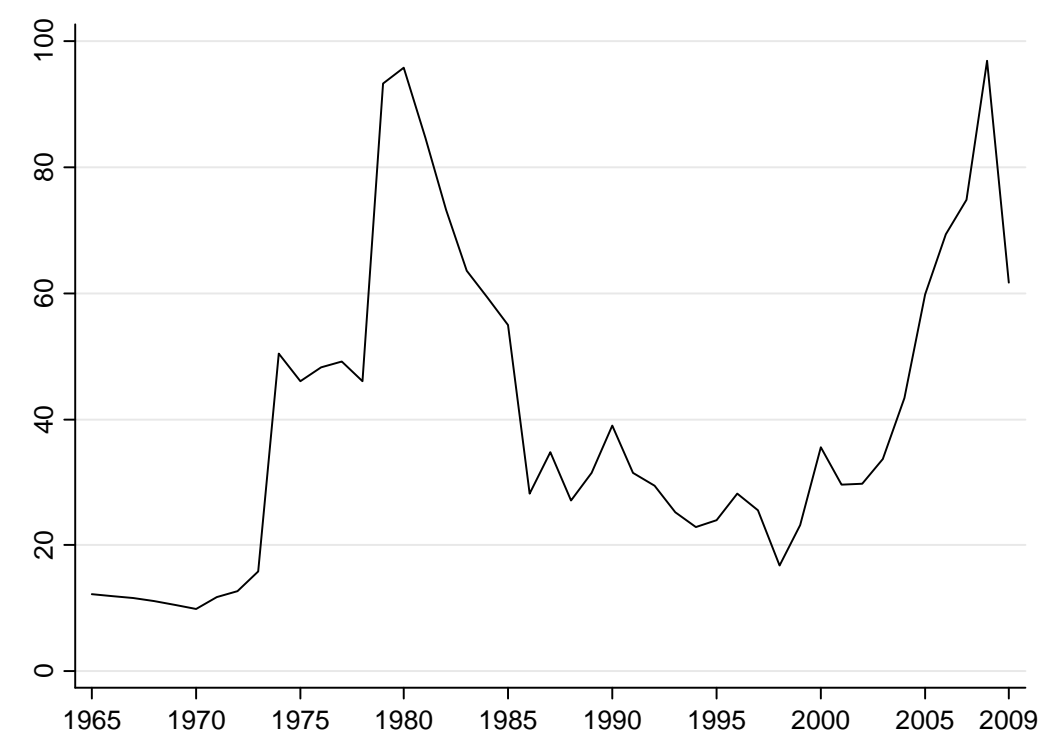

Notes: The figure is based on data from British Petroleum (2010).

Figure 4: Total Resource and Proven Reserves, 1980-2009

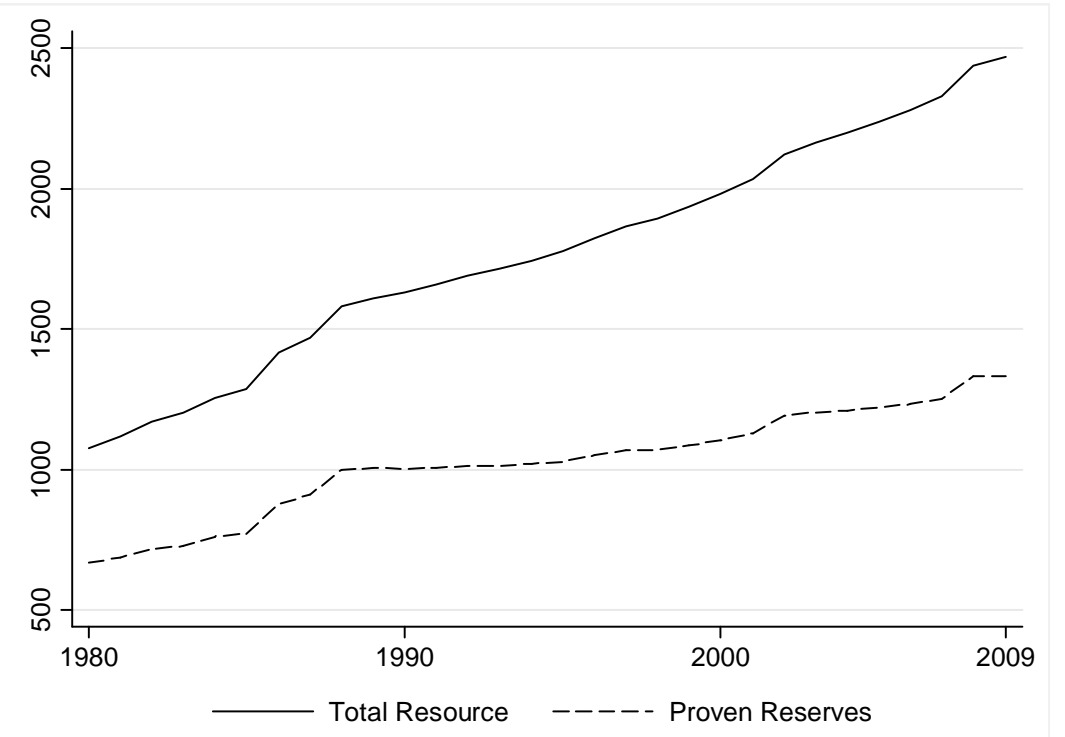

Notes: Total resource and proven reserves are in billion barrels. Total resource is defined as the sum of proven reserves and cumulative production at any given time. Author's calculations based on data from British Petroleum (2010) and OPEC (2010), see Section 4.1 for more details. 
Table 4: Cost Function Estimation Results, 1975-2008

\begin{tabular}{|c|c|c|c|}
\hline & Pooled OLS & Random Effects & Fixed Effects \\
\hline Marginal Cost & $\begin{array}{c}5.117^{* * *} \\
(0.049)\end{array}$ & $\begin{array}{c}5.107^{* * *} \\
(0.158)\end{array}$ & $\begin{array}{c}5.112^{* * *} \\
(0.046)\end{array}$ \\
\hline$\left(Q_{i t-1}\right)^{2} / q_{i t}$ & $\begin{array}{c}0.366 \times 10^{-3^{* * *}} \\
\left(0.028 \times 10^{-3}\right)\end{array}$ & $\begin{array}{c}0.375 \times 10^{-3^{* * *}} \\
\left(0.044 \times 10^{-3}\right)\end{array}$ & $\begin{array}{c}0.377 \times 10^{-3^{* * *}} \\
\left(0.047 \times 10^{-3}\right)\end{array}$ \\
\hline No. Countries/Observation & 1852 & $57 / 1852$ & $57 / 1852$ \\
\hline $\bar{R}^{2}$ & 0.22 & 0.22 & 0.22 \\
\hline
\end{tabular}

Notes: The dependent variable is the average cost of extraction, $A C_{i t}$. Standard errors are presented below the corresponding coefficients in brackets. Symbols $* * *,{ }^{*}$, and ${ }^{*}$ denote significance at $1 \%, 5 \%$, and at $10 \%$ respectively. The 57 countries used in the cost estimations are denoted by ${ }^{1}$ in Table 1. Source: Author's estimations, see Section 4.2 .1 for more details.

Table 5: Demand Function Estimation Results, 1965-2009

\begin{tabular}{lcc}
\hline & CMG & CPMG \\
\hline Income Elasticity $\left(\widehat{\mu}_{1}\right)$ & $\begin{array}{c}0.932^{* * *} \\
(0.423)\end{array}$ & $\begin{array}{c}0.678^{* * *} \\
(0.034)\end{array}$ \\
& 0.068 & $-0.150^{* * *}$ \\
Price Elasticity $\left(\widehat{\mu}_{2}\right)$ & $(0.335)$ & $(0.009)$ \\
& $-0.393^{* * *}$ & $-0.279^{* * *}$ \\
Error Correction Term $(\widehat{\theta})$ & $(0.047)$ & $(0.039)$ \\
& $65 / 2443$ & $65 / 2443$ \\
No. Countries / No. Observations & 0.74 & {$[p=0.69]$} \\
Joint Hausman Test & & \\
\hline
\end{tabular}

Notes: All estimations include a constant country specific term. Standard errors are presented below the corresponding coefficients in brackets. Symbols $* * *, * *$, and $*$ denote significance at $1 \%, 5 \%$, and at $10 \%$ respectively. The dependent variable is the growth rate of oil consumption per capita. The Schwarz Bayesian Criterion (SBC) has been used to select the lag orders for each group in which the maximum lag is set to two. The p-value is presented next to the corresponding h-test in square-brackets. Source: Author's estimations, see Section 4.2 .2 for more details. 
Table 6: Terminal Price of Oil in 2009 US Dollars, 2000-2010

\begin{tabular}{|c|c|c|c|c|c|c|}
\hline \multirow[b]{2}{*}{ Year } & \multirow[b]{2}{*}{$T R_{t}$} & \multicolumn{3}{|c|}{$P_{t, T_{t}}^{*}$ with $\delta=0.00075$} & \multicolumn{2}{|c|}{$P_{t, T_{t}}^{*}$ with $r=0.015$} \\
\hline & & $r=0.01$ & $r=0.015$ & $r=0.02$ & $\delta=0.00057$ & $\delta=0.00094$ \\
\hline 2000 & 1984 & 154.60 & 104.77 & 79.85 & 80.25 & 129.26 \\
\hline 2001 & 2035 & 158.50 & 107.37 & 81.81 & 82.22 & 132.50 \\
\hline 2002 & 2123 & 165.14 & 111.79 & 85.12 & 85.55 & 138.01 \\
\hline 2003 & 2164 & 168.21 & 113.84 & 86.66 & 87.09 & 140.56 \\
\hline 2004 & 2198 & 170.78 & 115.56 & 87.95 & 88.39 & 142.70 \\
\hline 2005 & 2238 & 173.73 & 117.53 & 89.42 & 89.87 & 145.15 \\
\hline 2006 & 2281 & 176.97 & 119.69 & 91.04 & 91.50 & 147.84 \\
\hline 2007 & 2330 & 180.68 & 122.16 & 92.90 & 93.36 & 150.92 \\
\hline 2008 & 2439 & 188.91 & 127.64 & 97.01 & 97.50 & 157.76 \\
\hline 2009 & 2470 & 191.22 & 129.18 & 98.16 & 98.66 & 159.67 \\
\hline 2010 & 2513 & 194.48 & 131.36 & 99.80 & 100.30 & 162.38 \\
\hline
\end{tabular}

Notes: Total reserves, $T R_{t}$, are in billion barrels and are calculated as the sum of cumulative production and proven reserves, at any point in time, using data from British Petroleum (2010) and OPEC (2010). The marginal cost, $\alpha$, is set equal to 5.11 based on the estimations in Section 4.2.1. The 95 percent confidence interval of $\delta$ is used to calculate the fourth and fifth columns. Source: Author's estimations, see Section 4.3 for more details. 
Figure 5: Extraction (leftscale) and Price (rightscale) Profiles, 2011-2044

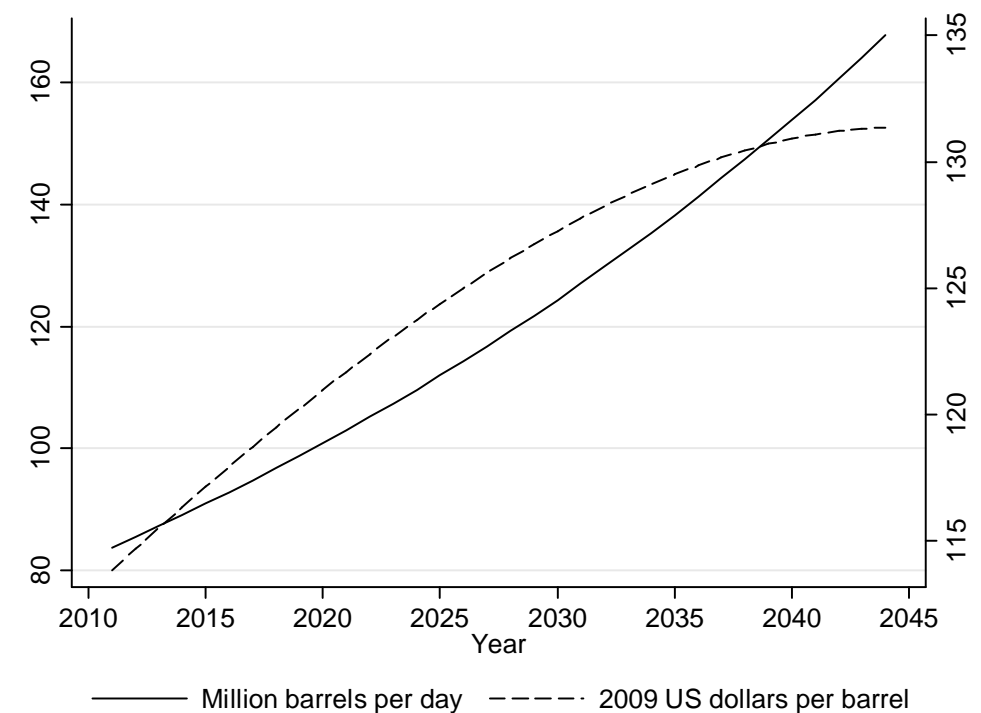

Notes: Author's estimations, see Section 5 for more details.

Figure 6: Extraction Profiles with the Share of Oil Falling

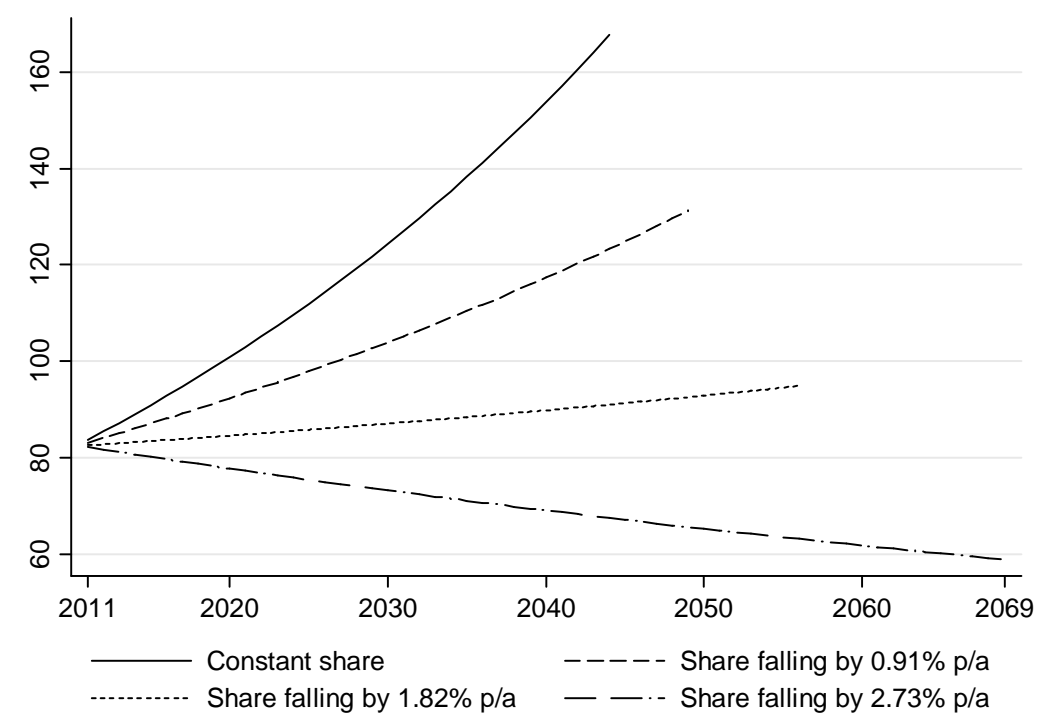

Notes: Oil extraction is in million barrels per day. The share of oil is assumed to be falling at the rate of X percentage points per annum. Source: Author's estimations, see Section 5.2.1 for more details. 
Figure 7: EIA (2011-2035) and Model (2011-2049) Extraction Projections

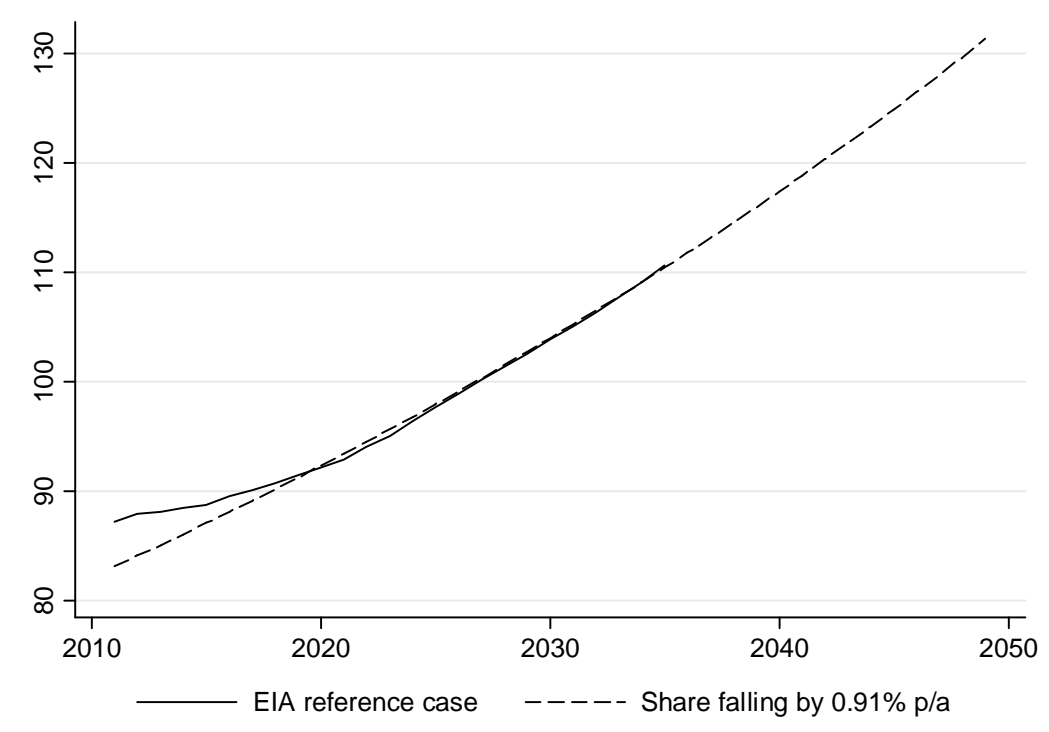

Notes: Oil extraction is in million barrels per day. Source: Author's estimations (see Section 5.2.1) and the Energy Information Administration (2010) International Energy Outlook.

Figure 8: Price Profiles with the Share of Oil Falling

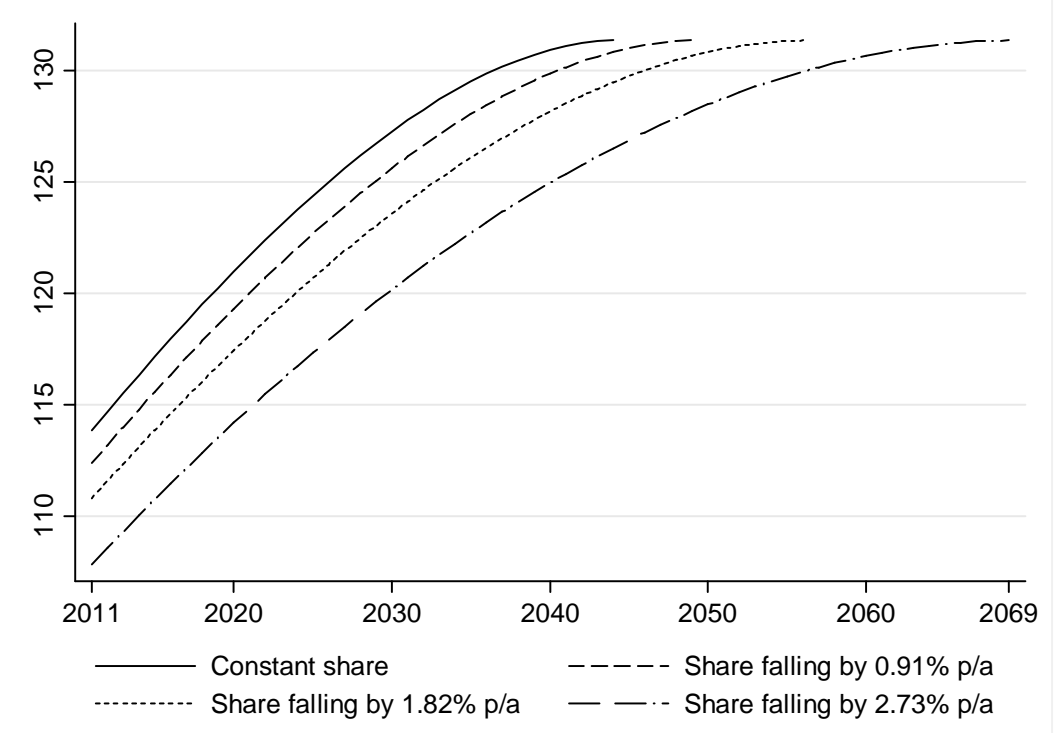

Notes: Oil prices are in 2009 US dollars. Source: Author's estimations, see Section 5.2.1 for more details. 